\title{
Employment experiences of vocationally trained doctors
}

\author{
Kay Osler
}

Abstract

Objectives-To investigate the expectations and employment experiences of male and female doctors who completed vocational training in East Anglia during 1981-7 and to examine the factors which had influenced those who had changed direction early in their careers.

Design-Survey conducted by confidential postal questionnaire.

Setting-Britain.

Subjects-281 doctors, $233(83 \%)$ of whom responded.

Main outcome measures-Ideal choice of work on completion of vocational training; present employment; factors which had restricted present choice of work; factors associated with reported satisfaction with job.

Results-77/83 (93\%) men and 130/150 (87\%) women had hoped to work in general practice $(p=$ $0.75)$. A smaller proportion of women $(71 \% ; 106)$ than men $(89 \% ; 74)$ were in general practice posts $(p<0.01)$; only $6 \%$ (nine) of women were on maternity leave or caring for children without paid employment. More women than men were working in medical jobs other than general practice $(18 \%(27)$ women $v 4 \%$ (three) men; $p<0 \cdot 01$ ). 44/91 (49\%) women with children had achieved their employment goals compared with $47 / 59$ (80\%) women without children and $55 / 71(78 \%)$ men with children. $87 \%(72 /$ $83)$ of men and $65 \%(98 / 150)$ of women had achieved the status of principal $(p<0.01) .162 / 193(84 \%)$ doctors who had worked in general practice reported satisfaction with their jobs. Dissatisfaction was linked with doing a job different from that hoped for and with perceiving that the share of practice income did not accurately reflect their share of the practice workload.

Conclusions-Steps need to be taken to retain women in general practice, including a statutory part time pay allowance and incentives for practices to allow flexible working hours for doctors with young children.

\section{Introduction}

The new contract for general practitioners promised to encourage "flexible working to help doctors unable to commit themselves to full time general practice." But at the same time changes were imposed making it harder than before for general practitioners to fulfil the criteria for full time status and therefore to claim the full basic practice allowance. The minimum hours of availability were increased from 20 to 26 hours to be spread over five days a week, doctors now having to contract with their family health services authorities to be available between specified hours. Simultaneously the payment for the employment of an assistant was increased, which it was admitted would "not be of direct benefit to doctors working on a part time basis."

I studied the expectations and employment experi- ences of a group of vocationally trained doctors in February and March 1990, immediately before the new contract came into effect, and examined the factors which 'influenced doctors' satisfaction with their jobs and the factors that had influenced those who had changed direction early in their careers.

\section{Subjects and methods}

I sent a questionnaire to 281 doctors who had completed general practice vocational training in East Anglia during the years 1981-7. During these years roughly 60 doctors a year trained in the region. The proportion of male to female trainees reflected the national figures of $60 \%$ men to $40 \%$ women. $^{2}$

The names of relevant doctors were obtained from lists held by the regional adviser in general practice. A stratified sample of former trainees was chosen, comprising all female trainees and a one third sample of the male trainees who completed vocational training. Male doctors were randomly selected by using a table of random sampling numbers. Twice as many women as men were surveyed as it was expected that most men would be working full time and that roughly half the women would be in part time posts.

The previously piloted confidential questionnaire was sent to the address in the current Medical Register and a reminder was sent two weeks later. When a doctor either could not be traced in the register or failed to respond to the initial mailings more up to date information was obtained when possible from his or her former trainer. Questionnaires and reminders were sent to all doctors for whom new addresses were obtained. A further questionnaire was sent to all nonresponders six weeks after the initial mailing followed by a final reminder two weeks later.

\section{DATA ANALYSIS}

$\chi^{2}$ values were used to analyse the differences in the results for male and female trainees. Data from the questionnaires were analysed with the statistical package for the social sciences (SPSS/PC).

The relation between the workloads and pay of part time profit share general practitioners was examined as follows. All profit share general practitioners were asked to give details of their own workload and details of that of their most full time partner, in terms of daytime work (surgeries, clinics, and other work which earned money for the practice) and personal out of hours commitment (night duty and weekend duty rotas) and to give details of how their own share of partnership profits at parity compared with that of their most full time partner. For each of the part time profit share general practitioners individual pay was calculated as a percentage of the pay received by the most full time partner in the same practice (percentage of a full profit share). Similar calculations were performed to obtain figures for the percentages of a full daytime workload and of full out of hours commitment. 


\section{Results}

Questionnaires were sent to 99 male and 182 female doctors. Eighty three men $(84 \%)$ and 150 women $(82 \%)$ responded. A significantly greater proportion of women $(29 / 150 ; 19 \%)$ than men $(3 / 83 ; 4 \%)$ had remained single $(p=0 \cdot 001)$. The group of single men was too small to be analysed separately. Ninety per cent (75) of men and $84 \%$ (126) of women were aged under 40 years.

At the time they completed vocational training men and women had hoped for similar employment: $93 \%$ (77) of men and $87 \%$ (130) of women had planned to work in general practice and $2 \%$ (two) of men and $11 \%$ (16) of women sought posts in some other branch of medicine ( $p=0.75$; table I). Eight per cent (seven) of men and $54 \%(81)$ of women wanted part time employment.

\section{FACTORS INFLUENCING CAREER}

Despite their originally similar career goals at the time of this survey, 2-9 years after completing vocational training, the female doctors were significantly less likely than their male contemporaries to be doing the job they had hoped for. Nearly one third of the women trained were not working in general practice, although only $6 \%$ (nine) of women were on maternity leave or caring for children without other paid employment. A significantly greater proportion of women than men were working in medical jobs other than general practice $(\mathrm{p}<0.01$; table I)

Of those doctors with a general practice post, $5 \%$ $(4 / 74)$ of men and $54 \%(57 / 106)$ of women were working less than full time. Of the married women working in general practice, two thirds $(65 \%)$ were working less than full time. There was no significant difference in the length of time taken by married males and single and married females to find their first jobs in general practice after completion of vocational training. Married women made significantly fewer job applications than their married male and single female colleagues $(p=0.001$; table II)

Men were significantly more likely than the women to have obtained posts as principals $(72 / 83(87 \%)$ men $v$ $98 / 150(65 \%)$ women; $p<0 \cdot 01)$. Of the women principals, three $(3 \%)$ were salaried partners. Women were more likely than men to be working as assistants or locums or to be on the general practitioner retainer scheme.

Twenty four per cent (20/83) of men and 39\% (59/ 150 ) of women reported that they were doing a job different from their original ideal choice of work $(p=$ $0.02)$. When asked specifically how much marriage had restricted or changed their choice of work $25 \%(19 / 75)$ of married men and $42 \%(45 / 107)$ of married women reported that their marriage had had a considerable effect. Many women commented that they had been

TABLE I-Doctors' ideal choice of work on completion of vocational training and present employment. Figures are numbers (percentages)

\begin{tabular}{lcccccc}
\hline & \multicolumn{2}{c}{$\operatorname{Men}(\mathbf{n}=83)$} & & \multicolumn{2}{c}{ Women $(\mathbf{n}=150)$} \\
\cline { 2 - 3 } \cline { 5 - 6 } & Ideal choice & Present work & & Ideal choice & Present work \\
\hline General practitioner & $77(93)$ & $74(89)$ & & $130(87)$ & $106(71)$ \\
Other medical job & $2(2)$ & $6(7)$ & & $16(10)$ & $27(18)$ \\
Non-medical job & $4(5)$ & $3(4)$ & & $3(2)$ & $8(5)$ \\
Child care or maternity leave & & & & $1(1)$ & $9(6)$ \\
\hline
\end{tabular}

TABLE II - Numbers (percentages) of married men, single women, and married women making numbers of job applications to find their firs jobs in general practice

\begin{tabular}{lccc}
\hline No of applications & $\begin{array}{c}\text { Married men } \\
(\mathrm{n}=72)\end{array}$ & $\begin{array}{c}\text { Single women } \\
(\mathrm{n}=26)\end{array}$ & $\begin{array}{c}\text { Married women } \\
(\mathrm{n}=88)\end{array}$ \\
\hline $1-5$ & $38(53)$ & $14(54)$ & $78(89)$ \\
$6-10$ & $10(14)$ & $2(8)$ & $2(2)$ \\
$>10$ & $24(33)$ & $10(38)$ & $8(9)$ \\
\hline
\end{tabular}

TABLE III -Current employment of married men, single women, and married women compared with their ideal choice of work at the time they completed vocational training. Figures are numbers (percentages)

\begin{tabular}{lccc}
\hline Work & $\begin{array}{c}\text { Married men } \\
(\mathrm{n}=75)\end{array}$ & $\begin{array}{c}\text { Single women } \\
(\mathrm{n}=29)\end{array}$ & $\begin{array}{c}\text { Married women } \\
(\mathrm{n}=107)\end{array}$ \\
\hline Different from ideal & $19(25)$ & $6(21)$ & $51(48)$ \\
Same as ideal & $56(75)$ & $23(79)$ & $56(52)$ \\
\hline
\end{tabular}

TABLE IV-Number (percentage) of doctors with different jobs and with children aged 5 or less according to age and sex

\begin{tabular}{|c|c|c|c|c|c|}
\hline & \multicolumn{3}{|c|}{ Women } & \multicolumn{2}{|c|}{ Men } \\
\hline & $\begin{array}{c}30-34 \\
(n=69)\end{array}$ & $\begin{array}{c}35-39 \\
(\mathbf{n}=51)\end{array}$ & $\begin{array}{c}\geqslant 40 \\
(\mathrm{n}=24)\end{array}$ & $\begin{array}{c}30-34 \\
(n=34)\end{array}$ & $\begin{array}{c}35-39 \\
(n=41)\end{array}$ \\
\hline General practitioner & $53(77)$ & $28(55)$ & $21(88)$ & $31(91)$ & $37(90)$ \\
\hline Other medical job & $11(16)$ & $13(25)$ & $2(8)$ & $3(9)$ & $2(5)$ \\
\hline Non-medical job & $2(3)$ & $5(10)$ & $1(4)$ & & $2(5)$ \\
\hline Child care & $3(4)$ & $5(10)$ & & & \\
\hline Had children aged $\leq 5$ & $34(49)$ & $30(59)$ & $2(8)$ & $27(79)$ & $29(71)$ \\
\hline
\end{tabular}

Women aged $<30$ and men $\geqslant 40$ not included.

tied geographically by their husbands' jobs. The current employment of married women was significantly more likely than that of married men or single women to be different from their ideal choice of work at the time they had completed vocational training ( $p=$ $0 \cdot 001$; table III).

Of those doctors with children, $20 \%$ (14/71) of men thought that their children had had an important effect on their career compared with $62 \%$ (56/91) of women $(\mathrm{p}<0.001)$. Women with children were the group least likely to be doing the work they had hoped for: only $49 \%$ (44/91) had achieved their employment goals compared with $80 \%$ (47/59) of women without children and $78 \%(55 / 71)$ of men with children. Men maintained a high rate of participation in medical work, especially general practice, despite having young children. The pattern of women's work differed from that of the men. A high proportion of women aged 30 $34(93 \% ; 64 / 69)$ and 40 and above $(96 \% ; 23 / 24)$ were employed in medical work. Only $80 \%(41 / 51)$ of women aged 35-39 were doing any medical work, and this was the group in which the most women had young children: nearly $60 \%$ (30) had children aged 5 and under. This age group had the smallest proportion of women $(55 \% ; 28 / 51)$ working in general practice; $25 \%$ (13) were doing other medical jobs, often working as clinical medical officers or in public and child health Only $10 \%$ (five) were caring for children without paid employment (table IV)

Of the men and women who were not doing their ideal choice of work, $10 \%(2 / 20)$ of men and 3\% (2/59) of women had changed their mind about the type of work they wanted and $10 \%(2 / 20)$ of men and $20 \%(12 /$ 59 ) of women had been unable to find a suitable job; $29 \%(6 / 20)$ of men and $12 \%(7 / 59)$ of women reported that they had left general practice because they had found the demands excessive or had been dissatisfied with their general practice post. Four of these seven women reported they had left because they had been underpaid as part time general practitioners.

Most doctors who had worked in general practice $(162 / 193 ; 84 \%)$ reported satisfaction with their posts Dissatisfaction was significantly linked with respondents doing a different job from that hoped for and to doctors reporting that the share of practice income they received did not accurately reflect their share of the practice workload.

Most of the doctors working full time $94 \%$ (103/110) believed that they were fairly paid relative to their workload. Those working part time more often reported being underpaid: $42 \%(22 / 53)$ of the part time profit share partners reported that their pay did not reflect their workload. 
RELATION BETWEEN WORKLOAD AND PAY

Of the 53 part time profit share partners, $18(34 \%)$ did no out of hours work. For this group the mean share of a full daytime workload undertaken was $71 \%$, compared with the mean percentage of a full profit share received of $42 \%$. For the 35 doctors who did out of hours work the mean share of a full daytime workload undertaken was $73 \%$ and the mean share of full out of hours commitment $61 \%$, whereas the mean percentage of a full profit share received was only $55 \%$.

\section{Discussion}

This study set out to examine the career goals and employment experiences of young doctors who had recently trained in general practice. Despite the finding that most men and women wished to continue working in general practice there was a contrast between the proportions of men and women who achieved this goal. This is consistent with the results of a concurrent survey. ${ }^{2}$

In recent years a rising proportion of doctors who undertake vocational training have been female. ${ }^{3}$ In keeping with previous research the women in this survey were less likely than the men to have changed their minds about the type of work they wanted or to have changed direction because they found the demands of general practice excessive. ${ }^{45}$ But nearly one third of the female doctors who had completed vocational training were no longer working in general practice. This loss cannot be attributed to lack of commitment. Few of the women in this study had stopped work even temporarily either because of their marriages or to care for their young children. This corresponds with the findings of other recent studies, which have emphasised the high rate of participation of women doctors in medical practice. ${ }^{36}$ If such large numbers of trained and motivated women are in future to continue doing the work they were trained for it is important to understand the particular employment problems they encounter.

Married women seem to have accepted jobs more readily than their contemporaries, a finding consistent with a previous study. 'But these posts were often less than ideal: many did not offer principal status, and even when doctors were appointed as part time profit share partners they received proportionately less pay than their full time partners for the work they had contracted to do. Although the discrepancy between the share of profits these doctors received and their share of daytime work could reflect the burden which out of hours work represents for full time general practitioners, this does not explain the fact that those part time doctors who did out of hours work received a considerably smaller share of profits than their share of either daytime or out of hours work. This suggests that some of these doctors were being underpaid. This disparity was an important source of discontent within this group, in keeping with recent research by Hooper et $a l,{ }^{8}$ and as a result some doctors left general practice.

Clearly women who are tied by their husbands' jobs yet wish to pursue their careers are in a weak negotiating position. National guidelines over pay for part time general practitioners might improve the present unsatisfactory situation. However, guidelines may not be enough. Although the British Medical Association has for several years recommended that general practitioners be appointed as profit share rather than salaried partners, such positions continue to exist, and a statutory part time pay formula seems to be needed.

Different problems arose for married women with young children, who were particularly likely to be working in other medical jobs. These doctors had accepted a change of medical employment when the needs of their children were greatest. Many commented on the relative convenience of their present work, contrasting it with general practice. A few of those who had stayed in general practice reported that they had negotiated favourable hours which may have allowed them to continue in their chosen work. More women with children might continue in general practice if their short term needs for flexible working hours could be more widely recognised and accommodated.

Little has been done in any specialty to meet the needs of the increasing numbers of women doctors in terms of part time training or flexible working arrangements. ${ }^{29}$ Job share arrangements introduced under the new contract ${ }^{\prime}$ are unlikely to help many women as the system is inflexible and depends on two doctors in the same area having exactly complementary and unchanging needs. But the structure of general practice, with small numbers of doctors within a group sharing the daytime workload and unsociable out of hours demands, makes providing convenient working hours for one partner disadvantageous to the others, who must take a heavier workload as a result. This problem needs to be recognised and financial incentives introduced to encourage practices to allow temporary short term flexible working arrangements for those who need them. Such changes would provide more opportunities for women to remain in general practice, and could also benefit some male doctors as changing attitudes make it increasingly likely that some fathers of young children will wish to take advantage of such a scheme.

The new contract has reduced the potential flexibility of all general practitioners' working arrangements and the income and status of those working part time. These factors have been shown to influence the proportion of women who remain in general practice after completing training. If increasing numbers of highly trained women doctors are not to be lost to general practice action must be taken. Vocational training schemes need to make women doctors aware of the difficulties they are likely to encounter in achieving their career objectives. Those women who have successfully negotiated satisfactory working conditions in general practice could be asked to share their experiences with those still in training posts. But the government and the General Medical Services Committee must recognise the extent of the present wastage of trained women general practitioners and the reasons for this.

This study was funded by a Royal College of General Practitioners Schering Scholarship and formed part of an MSc project in general practice at the United Medical and Denta Schools, London. The course fees were partly funded by the Clare Wand Fund and Glaxo Laboratories. I thank my supervisor, Dr Leone Ridsdale, for her support.

1 Health Departments of Great Britain. General practice in the national health service. The 1990 contract. London: HMSO, 1989.

Buchan J, Stock J. Early careers of general practitioners. London: Institute of Manpower Studies, 1990. (Report No 199.)
19rly

3 Allen I. Doctors and their careers. London: Policy Studies Institute, 1988.

4 Brown JM, Millar J, Mitchison H, Roberts P, Roberts S, Schofield P, et al. Newcastle vocational trainees 1976-80: are they doing the work they wanted? BMF 1983;286:353-6.

5 Cooper CL, Rout U, Faragher B. Mental health, job satisfaction, and job stress among general practitioners. $B M \mathcal{F} 1989 ; 298: 366-70$.

6 Wakeford RE, Warren VJ. Women doctors' career choice and commitment to medicine: implications for general practice. I R Coll Gen Pract 1989;39:91-5. North MA. Evaluation of the experiences of trainees seeking employment afte completion of their vocational training. I R Coll Gen Pract 1985;35:29-33.

8 Hooper J, Millar J, Schofield P, Ward AG. Part time women general practitioners-workload and remuneration. $\mathcal{F} R$ Coll Gen Pract 1989;39. 400-3

9 Warren VJ, Wakeford RE. "We'd like to have a family"-young women 1989;82:528-31.

(Accepted 12 fuly 1991 ) 